\title{
Nuevas interpretaciones del Paleolítico Superior Final de la Cataluña meridional: el yacimiento de L' Hort de la Boquera (Priorat, Tarragona)
}

\author{
New interpretations of the final Upper Palaeolithic of southern Catalonia: L'Hort de la \\ Boquera site (Priorat, Tarragona)
}

\author{
Pilar Garcia-Argüelles Andreu (*) \\ Jordi Nadal Lorenzo (*) \\ Josep M. ${ }^{a}$ Fullola Pericot (*) \\ M. ${ }^{\mathrm{a}}$ Mercè Bergadà Zapata (*)
}

\author{
Inés Domingo Sanz $(*)$ \\ Ethel Allué Martí (**) \\ Lluís Lloveras Roca (*)
}

\section{RESUMEN}

En este trabajo ofrecemos, por primera vez, los resultados obtenidos hasta el momento en las excavaciones en L'Hort de la Boquera, situado en Margalef de Montsant (Tarragona). El yacimiento forma parte del proyecto de investigación que llevamos a cabo sobre el poblamiento prehistórico del curso medio del río Montsant desde 1979. Los avances se centran en el estudio industrial, de paleoecología, de paleoeconomía, en las dataciones radiocarbónicas y, lo más novedoso, en el del arte mueble, así como en su adscripción a un Paleolítico superior final cuyas características particulares le diferencian del Magdaleniense clásico.

\begin{abstract}
This paper publishes for the first time the results of the excavations conducted at L'Hort de la Boquera site (Margalef de Montsant, Tarragona). This site is included in the research project we began in 1979 on the prehistoric settlement of the middle course of the Montsant River. We present the results obtained with respect to the lithic industries, palaeoecology, palaeeconomy, radio-
\end{abstract}

(*) Seminari d'Estudis i Recerques Prehistòriques (SERP), Departament de Prehistòria, Història Antiga i Arqueologia. Universitat de Barcelona. C/ Montalegre 6. 08001 Barcelona. Correos e.: garciaarguelles@ub.edu; jnadal@uoc.edu; fullola@ub.edu; lluislloveras@ub.edu; bergada@ub.edu; ines.domingo@ub.edu

(**) Institut Català de Paleoecologia Humana i Evolució Social (IPHES). Zona educacional 4, Campus Sescelades. Universitat Rovira i Virgili, edifici W3. E-43007 Tarragona. Correo e.: eallue@iphes.cat

Recibido: 26-III-2013; aceptado: 20-V-2013. carbon dates, and the latest discovery, an item of mobiliary art. These make it clear that the site belongs to the final Upper Palaeolithic, with specific features that partly distinguish it from the classic Magdalenian.

Palabras clave: Prehistoria; Paleolítico; Península Ibérica; Cazadores-recolectores; Paleolítico Superior final; L'Hort de la Boquera; Reconstrucción Paleoambiental; Arte mueble; Geoarqueología; Paleobotánica; Arqueozoologia; Dataciones radiocarbónicas.

Key words: Prehistory; Palaeolithic; Iberia; Huntersgatherers; Final Upper Palaeolithic; L'Hort de la Boquera; Paleoenvironmental evolution; Portable art; Geoarchaeology; Palaeobotany; Archaeozoology; Radiocarbon dating.

\section{INTRODUCCIÓN: SITUACIÓN Y MARCO GEOLÓGICO}

En este trabajo pretendemos ofrecer una visión global de los resultados obtenidos, hasta el momento, en el asentamiento de L'Hort de la Boquera. Forma parte del proyecto sobre el "Poblamiento prehistórico en el valle medio del río Montsant (Priorat, Tarragona)", que nuestro equipo está desarrollando desde el año 1979 en este y otros yacimientos pertenecientes al Paleolítico Medio (el Planot), al Paleolítico Superior (Els Colls, Cova del Boix o l'Hort de la Boquera), al Epipaleolítico (El Filadot) y al Neolítico (niveles superiores de La Bauma de l'Auferí). En la zona hay aún otros asentamientos que están por exca- 
var y donde pensamos realizar algún tipo de intervención para tener una visión más amplia y global de su poblamiento prehistórico.

L'Hort de la Boquera (Fig. 1) se localiza en el valle medio del río Montsant, en la comarca del Priorat (Tarragona) y, más concretamente, en el municipio de Margalef de Montsant, a unos $300 \mathrm{~m}$ aguas arriba del pueblo, en la orilla derecha del río y sobre la terraza fluvial que denominamos T2 (20-25 m) (Garcia-Arguelles et al. 1993). Este abrigo de más de $9 \mathrm{~m}$ de longitud acogió un asentamiento humano. Los $4 \mathrm{~m}$ más alejados del fondo del abrigo han sido totalmente destruidos por la caída de un bloque de la visera. El yacimiento en sí tiene unos $5 \mathrm{~m}$ de longitud, $4 \mathrm{~m}$ de profundidad y 1,70 de altura (Fig. 2).

El valle medio del río Montsant constituye la parte más septentrional de la Sierra del Montsant integrada, a su vez, en la sierra Prelitoral catalana. Esta sierra, situada al sudoeste de la Depresión Central Catalana, tiene una longitud de 19 $\mathrm{km}$ y alturas que llegan a los $1.163 \mathrm{~m}$.

La Sierra del Montsant contiene sedimentos de diversas épocas geológicas. La zona principal es el resultado de la acumulación y compactación de un sistema fluvial que aportó cantos y otros materiales de menor entidad hasta una cubeta marítima que se fue llenando durante el Oligoceno. La presión cimentó esta masa que la orogenia posterior elevó, dejando al descubierto los conglomerados que alternan con materiales más blandos, areniscas, arcillas rojas y capas de yeso.

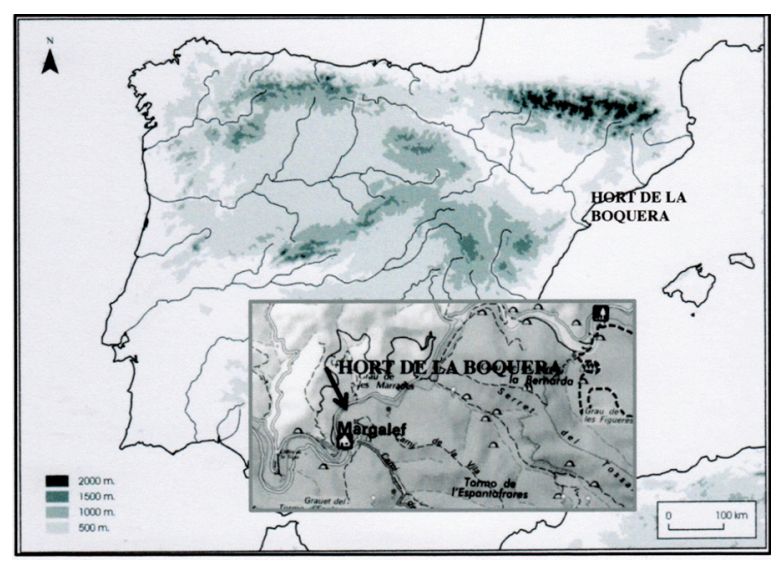

Fig. 1. Abrigo de l'Hort de la Boquera (Priorat, Tarragona). Situación en el valle medio del río Montsant y en la Península Ibérica.

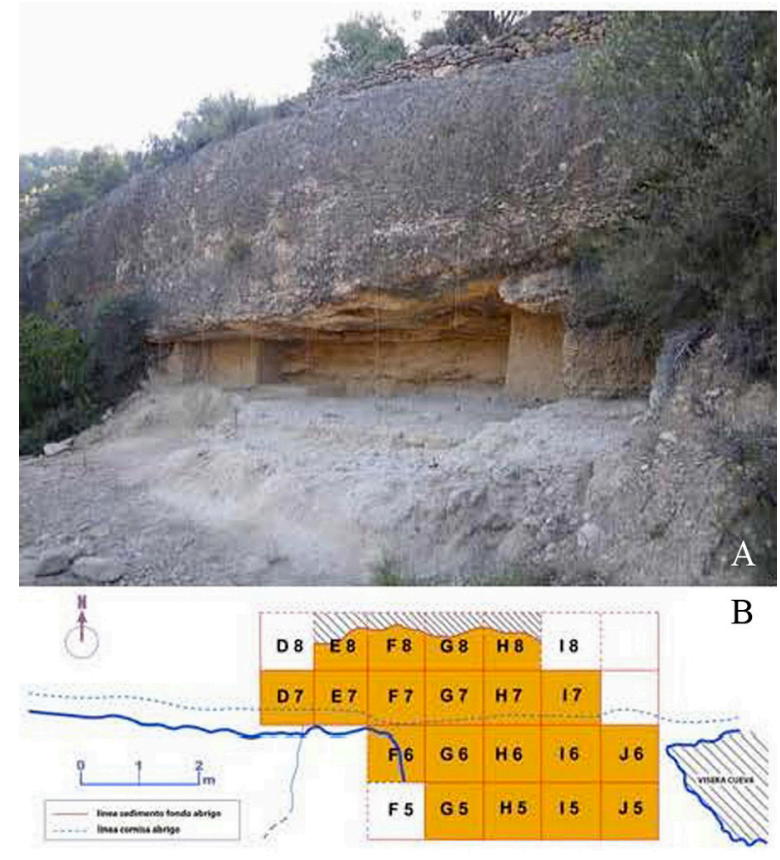

Fig. 2. Abrigo de l'Hort de la Boquera (Priorat, Tarragona): A. Vista desde el Este tras la campaña de 2012; B. Planta general tras las excavaciones de 2012.

La dureza diferencial de estas formaciones ha facilitado la aparición de numerosos abrigos, aprovechados por el ser humano durante las etapas intermedias de la Prehistoria. Gracias a la estructura geológica de la sierra del Montsant, aún encontrándose en un contexto árido, las fuentes y las surgencias de agua son muy abundantes, lo que, en su momento, facilitó la ocupación humana.

La zona se aleja del clima mediterráneo de baja montaña y encaja mucho mejor en los mediterráneos continentales de baja altitud: claro período de sequía estival y un mes claramente invernal, con temperaturas iguales o inferiores a $5 .^{\circ}$ Todo esto se conjuga con una inversión térmica en el valle del Montsant que da lugar a microclimas muy característicos.

\section{HISTORIA DE LAS INVESTIGACIONES}

L'Hort de la Boquera fue descubierto en 1979, durante unas prospecciones arqueológicas en la zona, iniciadas en el curso del programa de investigación, dirigido por uno de nosotros (JMFP), 
donde destaca la excavación del yacimiento epipaleolítico de El Filador.

En una de las terrazas del río Montsant, a unos $300 \mathrm{~m}$ del pueblo de Margalef de Montsant, se abría un pequeño abrigo que cerraba unos de los aterrazamientos artificiales construidos para plantar olivos. Unas informaciones de los vecinos del pueblo orientaron nuestras prospecciones a la superficie que se extendía delante del mismo, hallando abundantes materiales líticos, entre los que destacaban numerosos raspadores, elementos de dorso rebajado y núcleos. El sedimento se extendía a ambos lados de una incipiente cavidad, principalmente en el occidental, donde el sedimento superaba el límite actual del techo del abrigo (unos $12 \mathrm{~m}^{2}$ ).

Un corte estratigráfico para intentar encontrar una seriación estratigráfica y cronológica distinguió 4 niveles. El nivel I, estéril, tenía unos $4 \mathrm{~cm}$ y el sedimento era una aportación moderna. El nivel II (33-36 cm de potencia), arqueológico, era de coloración gris y muy compacto. El nivel III (38-31 cm), estéril, tenía coloración amarillenta. El nivel IV correspondía a la terraza del río (Fullola 1978).

La atribución cronológica no estaba muy definida. Algunas piezas tenían una apariencia auriñaciense (raspadores carenados y en hocico). En cambio la abundancia de elementos de dorso rebajado indicaba un momento más avanzado, propio bien de industrias que, entonces, consideramos como de la tradición gravetiense de la zona, bien de un Epipaleolítico microlaminar antiguo.

Al poco de su descubrimiento, una de nosotros (PGAA) delimitó una extensión de $6 \times 6 \mathrm{~m}$, donde recogió la totalidad del material en superficie. El estudio del conjunto de 1007 piezas, formado por lascas, núcleos, fragmentos, piezas retocadas y restos de talla, integró su tesis de licenciatura (1) y diversos artículos publicados por el equipo. En estos trabajos se consideró que el asentamiento formaba parte del Epipaleolítico microlaminar, sincrónico al que estábamos excavando en el cercano abrigo del Filador. Pero, a medida que profundizabamos en el análisis de las industrias y teníamos otros elementos de comparación en la zona, caso del abrigo de Els Colls (Fullola 1990),

(1) Garcia-Argüelles, P. 1983: Los talleres de sílex de superficie en el curso medio del río Montsant (Margalef de Montsant, Priorat), Universidad de Barcelona. se empezó a apuntar una atribución al Paleolítico Superior final.

Durante el verano de 1990 incluimos nuestra investigación en L'Hort de la Boquera en el programa Trobades amb la Ciència (Encuentros con la Ciencia) creado por la Generalitat. La dra M. ${ }^{a}$ M. Bergadà y el sr. R. Bartrolí, investigadores del grupo, coordinaron la actuación, auspiciada por la Comissió Interdepartamental de Recerca i Innovació Tecnologica (CIRIT). Se recogió el material arqueológico superficial en $10 \mathrm{~m}^{2}$ de la terraza sita delante del yacimiento, definiendo la estratigrafía en un perfil dejado por las labores agrícolas. El estudio constató que el sedimento pertenecía a la terraza T2 del río Montsant y el desarrollo de un paleosuelo en su parte superior. También se apuntaba, en Cataluña, una dualidad cultural en el Paleolítico Superior final: un Magdaleniense clásico en los yacimientos de El Parco (Alòs de Balaguer) o Bora Gran (Serinyà) y una facies menos clásica, que ya Jordá denominó Epigravetiense, caracterizada por la perduración de la tecnología y tipología del Gravetiense anterior (Bech et al. 1991).

En 1992, nuestro equipo hizo un sondeo aprovechando el perfil del año 1979, cuya estratigrafía trataremos en profundidad en el siguiente apartado. Analizamos también la sedimentología y obtuvimos una primera datación radiocarbónica (GIF10026: $9420 \pm 80 \mathrm{BP}$ ), a una profundidad de $100-110 \mathrm{~cm}$ respecto del nivel 0 del perfil. Según el laboratorio la muestra contenía mucha fracción húmica por lo que la fecha era más reciente de lo esperado. Esta información fue parte importante de una tesis doctoral posteriormente publicada (Bergadà 1998).

Los resultados de 1992 nos impulsaron a incluir L'Hort de la Boquera en 1998 en nuestras excavaciones programadas. En 1997, tras finalizar las 19 campañas ininterrumpidas en el abrigo del Filador (García-Argüelles et al. 2005), creímos que L'Hort de la Boquera proporcionaría interesantes datos complementarios, cronológica y culturalmente, de la secuencia fundamental de El Filador. Primero se abrieron los cuadros visibles tras la caída de la visera $\left(10 \mathrm{~m}^{2}\right) \mathrm{y}$, a partir de 2007, los $2 \mathrm{~m}$ de profundidad que quedaban ya propiamente bajo la visera del abrigo. Así en estos últimos años estamos excavando $19 \mathrm{~m}^{2}$ en extensión (Fig. 2B). 


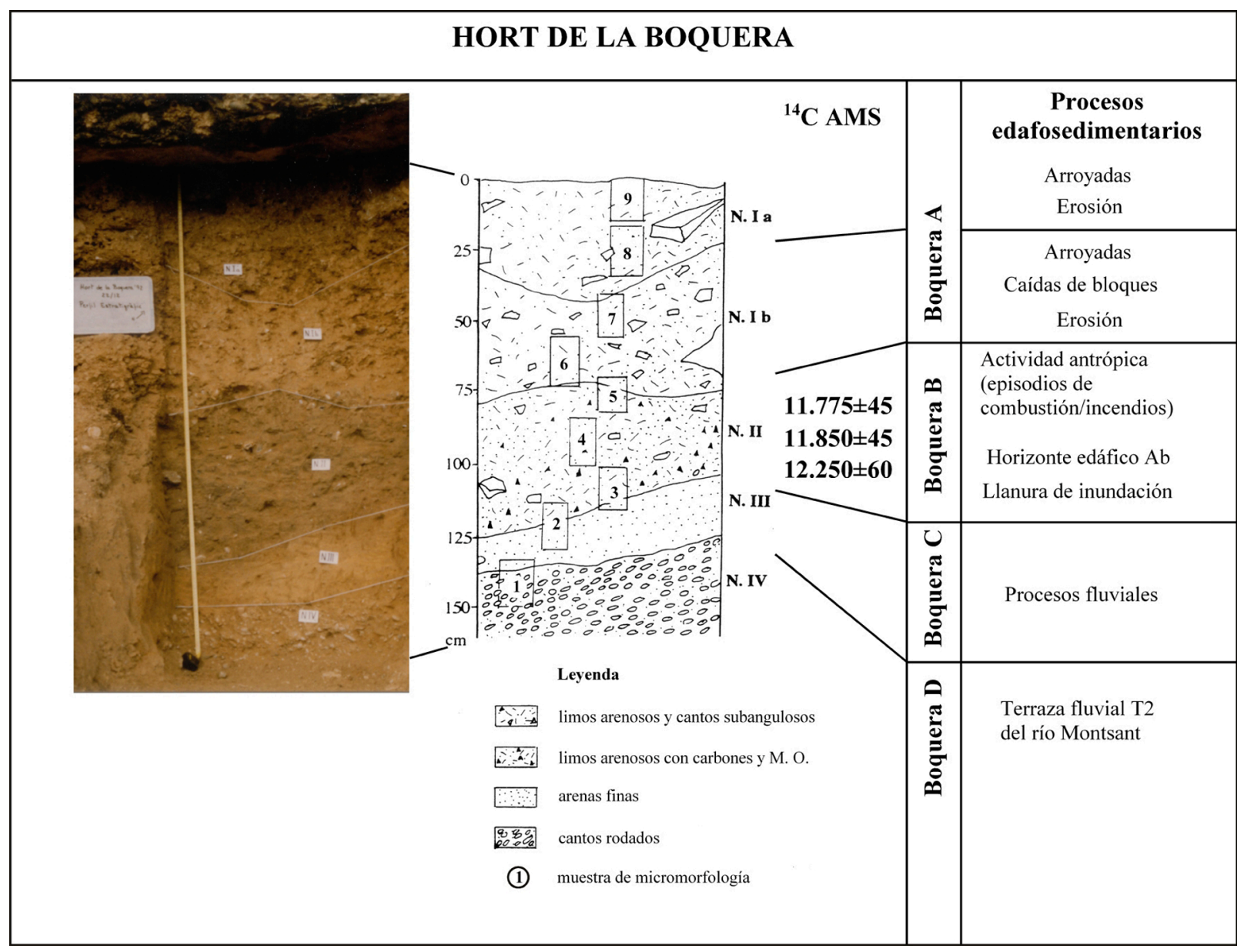

Fig. 3. Abrigo de l'Hort de la Boquera (Priorat, Tarragona). Perfil litoestratigráfico y procesos edafosedimentarios.

\section{MICROESTRATIGRAFÍA, SECUENCIA EDAFOSEDIMENTARIA Y PALEOCLIMÁTICA}

La secuencia del abrigo de L'Hort de la Boquera que presentamos en este artículo se basa principalmente en el estudio estratigráfico y sedimentario de campo y en el análisis micromorfológico de los perfiles de la cuadrícula E-7 (Bergadà 1998). Ello se ha completado con microscopía electrónica de barrido (ESEM-EDX) aplicada, en especial, a los niveles II y I.

La base de la secuencia descansa directamente sobre el depósito de terraza fluvial -T2- del río Montsant a 24,7 m sobre el lecho de su cauce actual (García-Argüelles et al. 1993; Bergadà et al. 1997; Bergadà 1998). Su techo alcanza en el sector E-7 hasta el estrato de conglomerado que configura la visera del abrigo. Allí la potencia supera $1,50 \mathrm{~m}$, mientras en otros ámbitos del yacimiento las tareas agrícolas recientes la han reducido. El registro comprende los siguientes niveles de muro a techo (Fig. 3):

Nivel IV: potencia $18 \mathrm{~cm}$ vistos. Está formado mayoritariamente por cantos y gravas cuya litología predominante son calizas, cuarcitas y esquistos de morfología redondeada, procedentes del río Montsant. Los cantos, de 1 a $6 \mathrm{~cm}$, aparecen con cierta imbricación en dirección $\mathrm{O}$. Se localizan ligeras trazas de concreción carbonatada. Su geometría es tabular.

Nivel III: potencia $12 \mathrm{~cm}$. En contacto neto con el anterior nivel, está compuesto principalmente por arenas finas de color marrón (10 YR 6/6) y gravas redondeadas de $2 \mathrm{~mm}$ a $1 \mathrm{~cm}$ de la misma litología que el nivel anterior, con una 
geometría ligeramente en forma de cuña. Contiene algún resto carbonoso y fragmentos de sílex.

Nivel II: potencia $47 \mathrm{~cm}$. Está constituido por una matriz de limos arenosos de color gris-pardo (10YR 5/2) con un 5\% de cantos dispersos de 1 a $2 \mathrm{~cm}$, en su mayoría, calizas de morfología redondeada a subredondeada, con ligeras concreciones de $\mathrm{CaCO}_{3}$. Se localizan trazas de carbonatación en forma de pseudo-micelios. El contacto con el nivel III es neto, y su geometría apunta también ligeramente a la forma de cuña. Contiene abundantes carbones, fragmentos óseos y de sílex.

Nivel I: se subdivide en dos. El subnivel $\mathrm{Ib}$ tiene $45 \mathrm{~cm}$ de potencia. Se dispone en contacto erosivo con el nivel II. Domina la matriz de limos arenosos de color marrón (10YR 6/4) con cantos subangulosos de $1 \mathrm{a} 4 \mathrm{~cm}$ de conglomerado y de caliza, con algún bloque procedente de la visera del abrigo. Se localiza actividad biológica, especialmente de raíces y de fauna. Disminuye considerablemente la presencia de carbones. El subnivel Ia de $42 \mathrm{~cm}$ de potencia, se dispone en contacto erosivo con el subnivel Ib. Respecto a $\mathrm{Ib}$, disminuye la fracción de cantos que ahora aparecen muy concrecionados. La matriz sigue siendo de limos arenosos de color marrón $(7,5$ YR 6/4). La actividad biológica se acentúa.

\subsection{Análisis micromorfológico}

El análisis micromorfológico sistemático abarca toda la secuencia (nivel IV a nivel Ia) en el sector E-7. Además, en el nivel II realizamos otro muestreo complementario, en extensión, en el cuadro I-6 para contrastar algunos datos extraídos del perfil en estudio y también por sus rasgos edafosedimentarios y antrópicos que le confieren una atención más detallada.

Se ha extraido un total de 10 muestras con un protocolo consistente en la introducción de unas cajas recubiertas de yeso en el sedimento con los que obtenemos bloques $\mathrm{cm}$ sin alterar la estructura y disposición del depósito (Bergadà 1998). El Departamento de Medio Ambiente y Ciencias del Suelo de la Universidad de Lleida hizo las láminas delgadas de $13,5 \times 5,5 \mathrm{~cm}$. Su descripción e interpretación sigue a los autores de referencia (Bullock et al. 1985; Courty et al. 1989; Stoops 2003; Stoops et al. 2010). Los rasgos más característicos de cada nivel son:
Nivel IV: está formado básicamente por cantos de conglomerado, caliza micrítica y bioclástica y esquisto, de morfología redondeada y tabular, y por arenas medianas y finas de cuarzo, feldespatos y calcita de morfología subangulosa. No aparecen componentes de origen antrópico. Destacan las cristalizaciones en forma de fibrasagujas de calcita, de tamaño submilimétrico, que aparecen mayoritariamente en huecos, y algún resto de raíz. Atribuimos este nivel al aluvionamiento del río Montsant, en un régimen de fuerte intensidad, que configura el depósito T2. E1 rasgo edáfico más característico son esas fibrasagujas de calcita (NFC-Needle fibre calcite), cuyo origen estaría relacionado con un proceso de biomineralización de hifas de hongos (Bajnóczi y Kovács-Kis 2006; Durand et al. 2010).

Nivel III: está compuesto por una matriz arenosa con fracción fina dominante. La litología y la mineralogía son como las del nivel IV. Hay carbones de morfología tabular subredondeada y nodular de color negro-rojizo, fragmentos de raíces y alguno de sílex. En los procesos edáficos, destacan las acumulaciones secundarias en forma de revestimientos de material fino y carbonoso alrededor de las partículas arenosas. También hay cristalizaciones de calcita en forma de fibrasagujas en los huecos, y trazas de la actividad biológica que se expresa principalmente como porosidad cavitaria. Este nivel también es de origen fluvial, pero en un régimen de menor intensidad que el anterior. Las circulaciones hídricas causan la disgregación del material carbonoso y su removilización alrededor del material detrítico. Las biomineralizaciones aparecen como cristalizaciones de calcita en los poros.

Nivel II: está constituido por una matriz de limos arenosos, junto a cantos de morfología redondeada y subredondeada. La fracción gruesa presenta trazas de disolución (contornos irregulares). La composición mineralógica y litológica es como la de los anteriores niveles. Algunos fragmentos detríticos tienen, especialmente en las M.3 y M.4, numerosas trazas de combustión como la fragmentación y opacidad del material calizo y las impregnaciones de óxidos e hidróxidos de hierro (Fig. 4A). La porosidad es mayor que en los niveles anteriores, y la microestructura va de granular a prismática. Aumentan los restos carbonosos $(250 \mu \mathrm{m}-1 \mathrm{~mm})$ de morfología tabular con una estructura celular leñosa bien visible (Fig. 4B) y con algún resto calcítico, que

Trab. prehist., 71, N. ${ }^{\circ}$ 2, julio-diciembre 2014, pp. 242-260, ISSN: 0082-5638

doi: $10.3989 /$ tp.2014.12133 

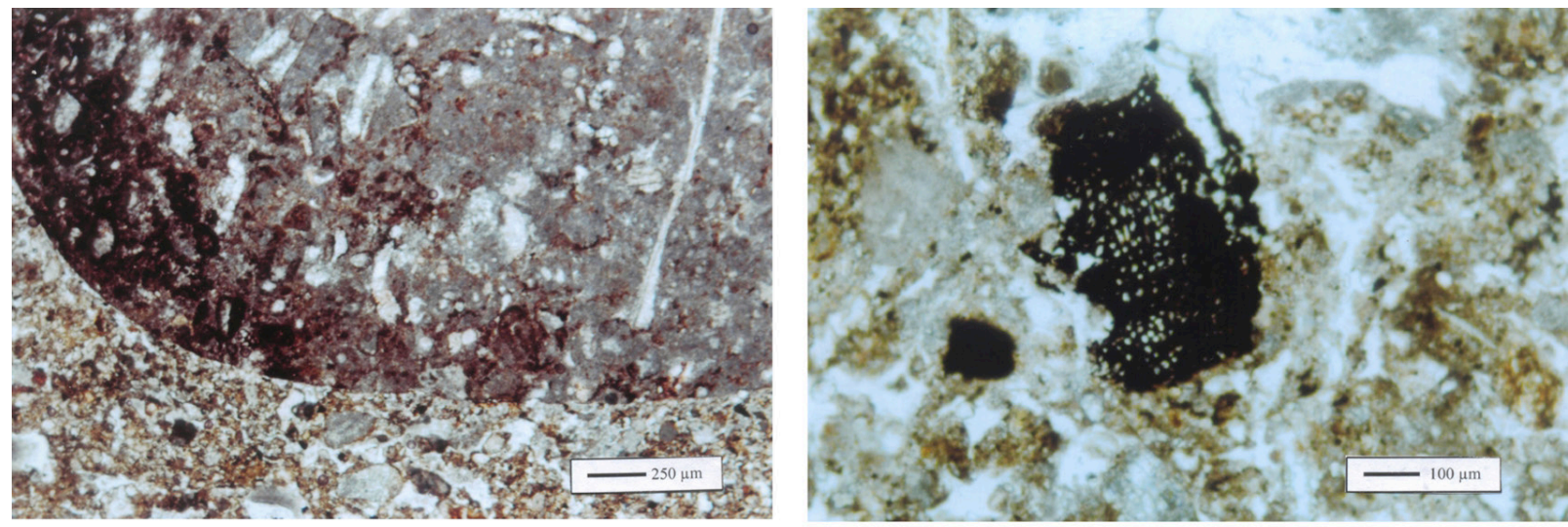

A

B
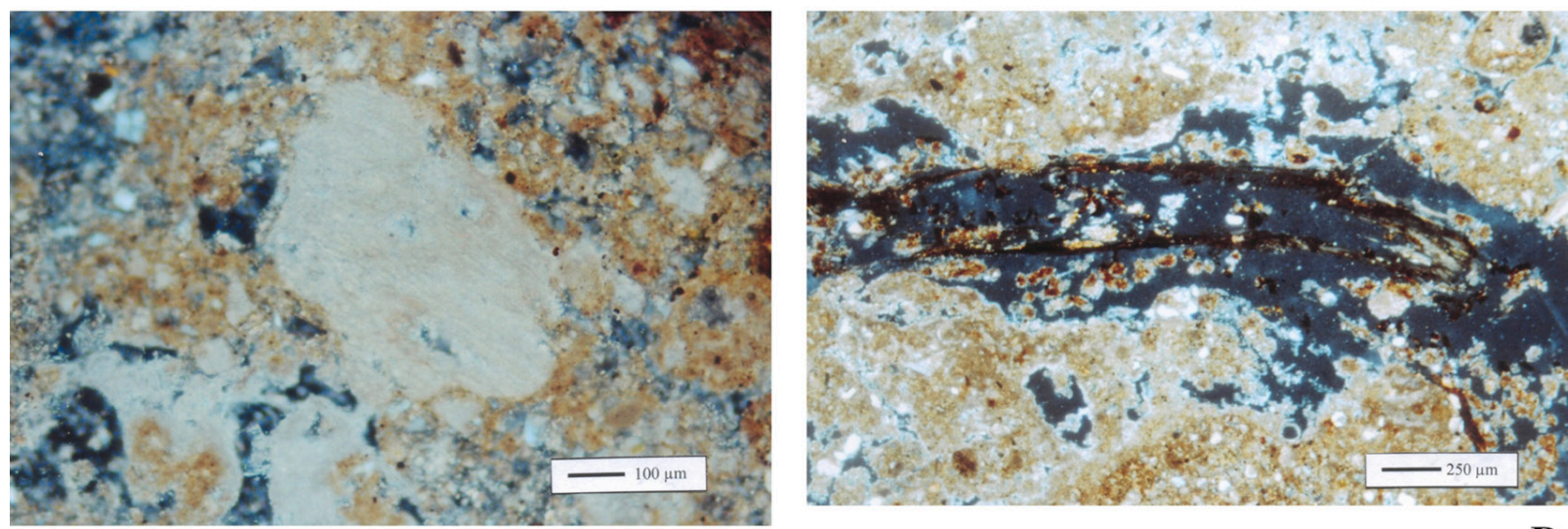

C

D
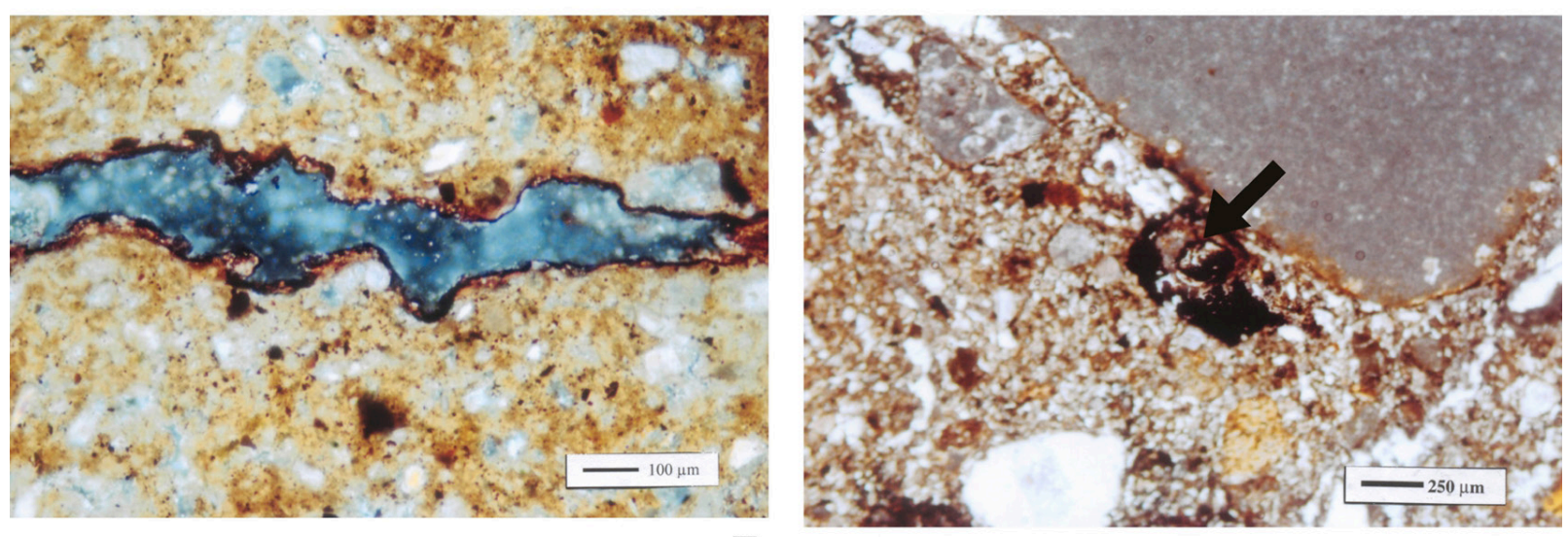

$\mathbf{E}$

Fig. 4. Abrigo de L'Hort de la Boquera (Priorat, Tarragona). Nivel II: A. Fragmento de caliza con impregnaciones de óxidos e hidróxidos de hierro debido a la combustión. LPP $(250 \mu \mathrm{m})$; B. Carbón con estructura leñosa. LPP (100 $\mu \mathrm{m})$; C. Resto calcítico de origen vegetal (ceniza). LPX $(100 \mu \mathrm{m})$; D. Sección longitudinal de raíz. Se conserva el córtex y muy débilmente el tejido interno. LPX $(250 \mu \mathrm{m})$; E. Sección longitudinal de raíz. Solo se localiza parte del córtex. LPX $(100 \mu \mathrm{m}) ; \mathrm{F}$. Sección transversal de raíz con residuos calcíticos (flecha) como resultado de la combustión. LPP $(250 \mu \mathrm{m})$. 
también conserva su estructura celular original (ceniza de origen vegetal), disperso por la masa basal (Fig. 4C). Igualmente aparecen, en cantidad considerable, residuos de materia orgánica (50 a $125 \mu \mathrm{m}$ ), en especial raíces con distintos grados de descomposición (Fig. 4D y E), algún resto de ceniza (Fig. 4F), huesos con distintas trazas de combustión, sí como fragmentos de sílex con impregnaciones de óxidos e hidróxidos de hierro. En los procesos edáficos, se acentúa la presencia de fibras-agujas de calcita en los canales de materia orgánica (Fig. 5A y B), asociadas a hiporrevestimientos calcíticos de 125 a $300 \mu \mathrm{m}$ de grosor (Fig. 5C). Las acumulaciones secundarias de material fino con carbones y residuos de materia orgánica rodean al material detrítico como hiporrevestimientos y revestimientos. Este nivel funcionaría principalmente como llanura de inundación del río Montsant con tasa de sedimentación baja. Este rasgo, junto a la concentración de materia orgánica procedente en su mayoría de raíces, lleva a la formación de un horizonte edáfico (Bech et al. 1990). Todo ello, junto al desarrollo de una fuerte actividad antrópica manifestada por varios episodios de combustión, conlleva el color oscuro de la matriz. La asociación de hiporrevestimientos calcíticos (impregnaciones de calcita en la matriz del suelo alrededor de los poros) con revestimientos en huecos de fibras-agujas de calcita indicaría la presencia de plantas superiores en dicho horizonte (Bajnóczi y Kovács-Kis 2006).

Nivel I: se han distinguido dos subniveles. El subnivel Ib está compuesto por una matriz de limos arenosos con cantos y bloques de conglomerado que aparecen en contacto con el nivel II. Los cantos de morfología subangulosa son de caliza con algunas fisuras y trazas de disolución (contornos irregulares) (Fig. 5D). Aparecen costras sedimentarias de limos arenosos. Disminuyen considerablemente los carbones y los restos de materia orgánica (raíces). En los procesos edáficos destacan las acumulaciones de $\mathrm{CaCO}_{3}$-micrita- junto a material detrítico pendents bajo la fracción gruesa de 250 a $750 \mu \mathrm{m}$ de grosor (Fig. $5 \mathrm{E}$ ), y los gránulos de calcita biogénica de $600 \mu \mathrm{m}$ a 1,5 mm (Fig. 5F). Aparecen, también, agregados y cámaras originados por la actividad de la fauna del suelo. El subnivel Ia está formado por una matriz de limos arenosos. Disminuye considerablemente la fracción de cantos y hay un aumento sensible de componentes de origen antrópico, como carbones y fragmentos de sílex. En los procesos edáficos, aparecen los mismos rasgos que en el subnivel Ib. Este nivel está formado por procesos de arroyadas, corroboradas por las costras sedimentarias con alguna caída de bloques de la visera del abrigo, en especial en el subnivel $\mathrm{Ib}$. Destacamos la fisuración de los cantos, en algún caso, acentuada por la intrusión de raíces, así como las acumulaciones de micrita junto a material detrítico muy fino bajo la fracción gruesa. Dichas precipitaciones se deberían a circulaciones de aguas enriquecidas en carbonatos que, junto a material detrítico, precipitarían sin una orientación de la cristalización de la calcita, muy posiblemente en un medio húmedo indicador de una mejora de las condiciones climáticas (Durand et al. 2010). Los gránulos de calcita biogénica aparecen con morfología esférica o elipsoidal, según sean seccionados transversal o longitudinalmente en lámina delgada. La disposición de las cristalizaciones de calcita de forma radial es propia de lumbrícidos (Durand et al. 2010).

\subsection{Discusión: caracterización edafosedimentaria y antrópica}

En la secuencia del abrigo del Hort de la Boquera se han distinguido 4 episodios edafosedimentarios (Fig. 3):

Boquera D, cantos y arenas: comprende el nivel IV, con una sedimentación de fuerte energía, con cantos rodados y arenas. Está sin duda ligado al segundo nivel (T2) de terrazas fluviales del curso medio del río Montsant que alcanza entre 20 y $25 \mathrm{~m}$ de altura respecto al lecho actual del cauce (Bergadà 1998).

Boquera $\mathrm{C}$, arenas finas: se caracteriza por un aporte sedimentario fluvial, donde el régimen hídrico disminuye de intensidad con arenas medianas y finas que constituyen el nivel III. Hay indicios de ocupación antrópica, como carbones y fragmentos de sílex. En la actualidad no podemos concretar más ya que la intervención arqueológica en curso se centra en los niveles superiores del yacimiento.

Boquera $\mathrm{B}$, limos arenosos de color gris oscuro con restos carbonosos y de materia orgánica: el nivel II representa este episodio caracterizado por un depósito de llanura de inundación, junto a restos de materia orgánica, principalmente procedente de raíces en distintos fases de humificación, y algunas de ellas con trazas de com- 


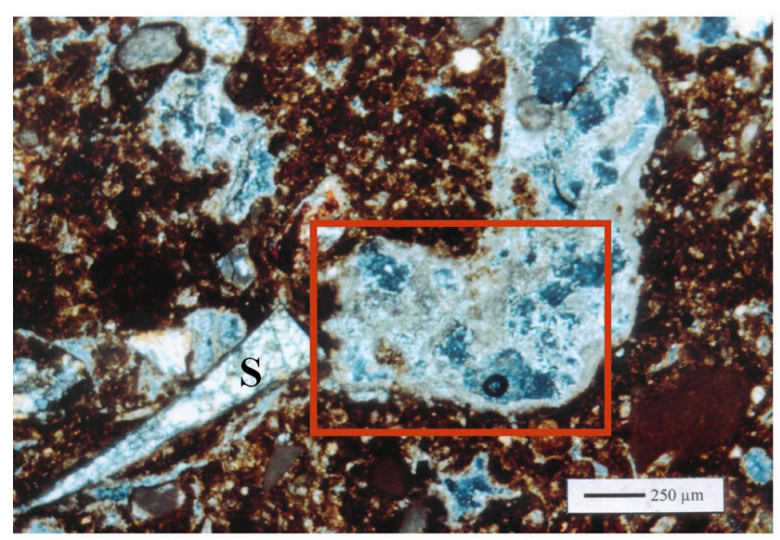

A

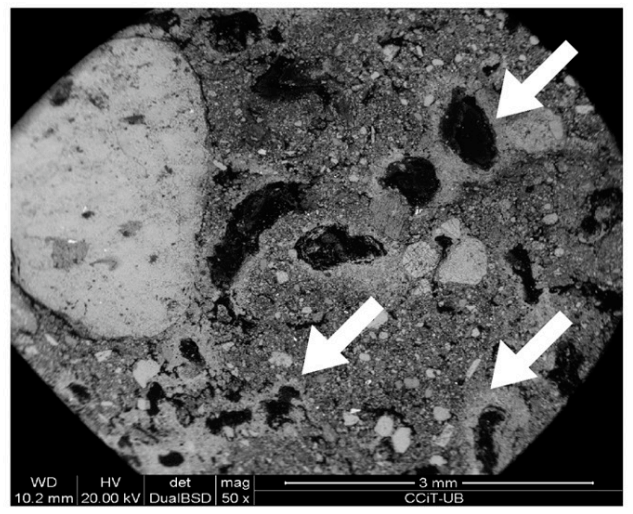

C

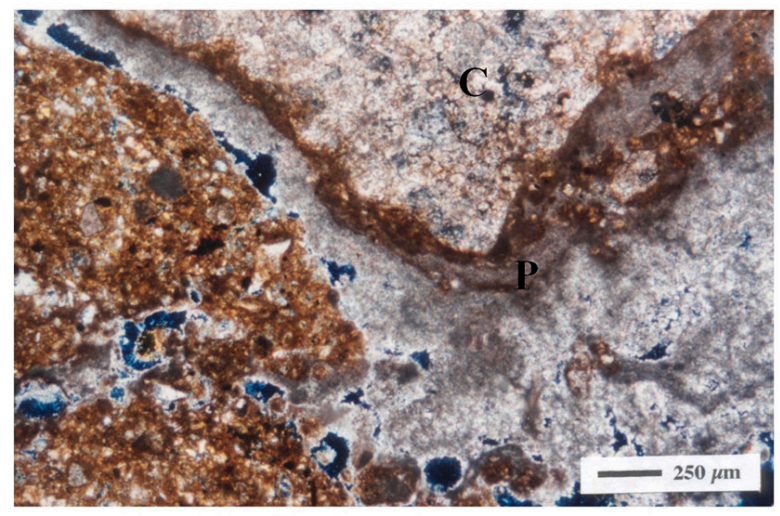

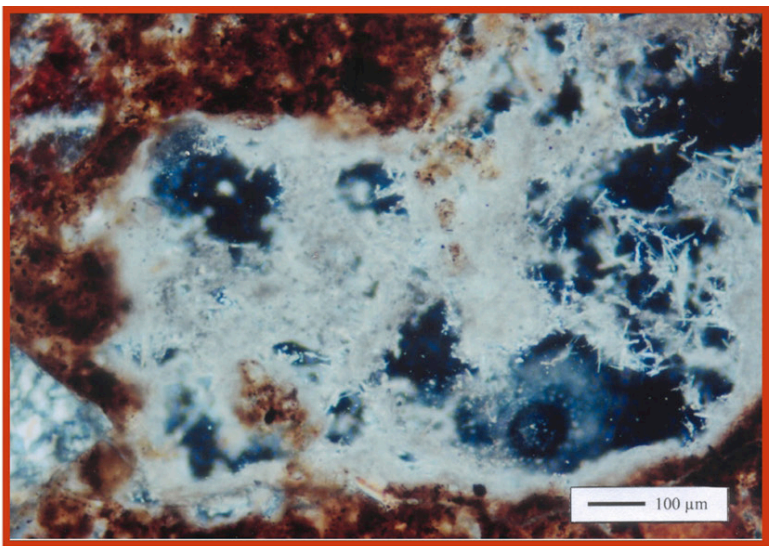

B

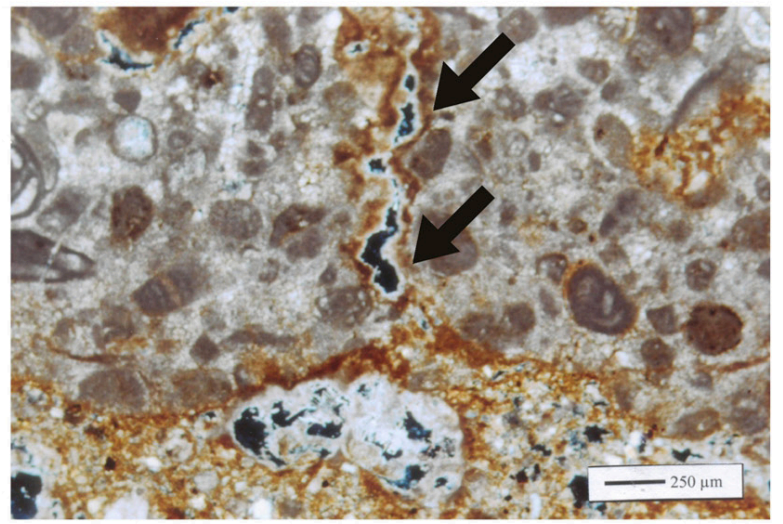

D

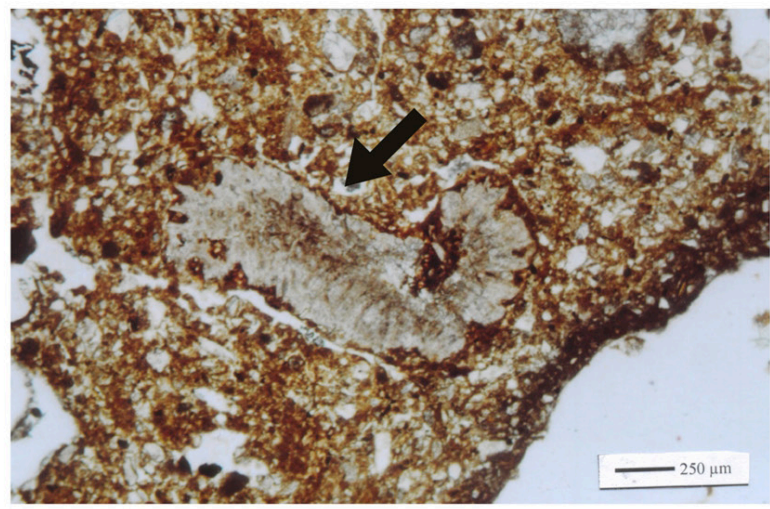

$\mathbf{F}$

Fig. 5. Abrigo de L'Hort de la Boquera (Priorat, Tarragona). Nivel II: A. Biomineralizaciones en forma de fibrasagujas en un poro, al lado aparece un fragmento de sílex (S). LPX $(250 \mu \mathrm{m})$; B. Detalle de la biomineralización anterior. LPX (100 m); Nivel II: C. Hiporrevestimientos calcíticos en los poros. ESEM; Nivel I: D. Trazas de disolución en un fragmento de caliza. LPX $(250 \mathrm{~m})$; F. Corte longitudinal de un gránulo de calcita biogénica (lumbrícido). LPP $(250 \mu \mathrm{m})$. 
bustión. Dada su concentración dicho nivel se considera un horizonte edáfico $-\mathrm{Ab}-$ de color oscuro y con estructura bien desarrollada. La documentación de biomineralizaciones de calcita en forma de fibras-agujas como proceso pedogenético indica un episodio de estabilidad y de acumulación orgánica que ha propiciado la actividad biológica principalmente de hongos. Su asociación con hiporrevestimientos calcíticos a lo largo de la secuencia de este horizonte puede vincular los hongos con plantas superiores. El rol de los hongos, según Verrecchia et al. 1994, podría conectarse con la descomposición de la materia orgánica putrefacta de las raíces. En cambio Wright (1986) los considera parásitos de las plantas o en relación simbiótica con ellas. En definitiva, la formación de dicho paleosuelo podría responder a un período de estabilidad, con reducida sedimentación y unas condiciones climáticas relativamente húmedas. Desde el punto de vista antrópico, en las muestras 3 y 4 se distingue una mayor concentración de restos de carbones de tipo leñoso, con algún resto de ceniza, huesos y elementos de sílex también con fisuraciones propias de combustión. Sus características sugieren que dicho horizonte responde a distintos episodios de quema, los cuales quedaron algún tiempo en superficie y fueron colonizados por plantas. Sus manifestaciones son los bioporos de origen vegetal con signos de combustión. Todo ello dificulta el aislamiento de las distintas ocupaciones.

Boquera $\mathrm{A}$, limos arenosos con cantos subangulosos: este episodio, nivel I, muestra un cambio muy importante respecto al anterior. Su contacto es irregular y de tipo erosivo. La formación responde a procesos de arroyadas, con alguna dis- gregación del techo del abrigo, especialmente en la base del nivel.

Los materiales y componentes de origen antrópico siguen apareciendo, pero disminuyen considerablemente. Deben tenerse en cuenta varios procesos postdeposicionales: las acumulaciones de $\mathrm{CaCO}_{3}$ bajo el material detrítico pendents, en especial en los cantos, la actividad biológica, sobre todo de los lumbrícidos, expresada en la formación de canales y cámaras, la alteración de la microestructura y redeposición del material detrítico (Bergadà 1993), así como la formación de gránulos de calcita biogénica. Los ejemplares de pendents que tenemos registrados responden a precipitaciones de $\mathrm{CaCO}_{3}$ de cristales de calcita no orientados, junto a un alto contenido de partículas detríticas finas. Este rasgo se produce durante el secado de los suelos, cuando hay una mayor retención de la humedad en las partes inferiores de los cantos y gravas. La actividad biológica, principalmente de lumbrícidos, indica, en registros arqueológicos, períodos de abandono y de cierta estabilidad del medio.

\subsection{Secuencia paleoambiental}

Hemos calibrado las fechas radiocarbónicas de L'Hort de la Boquera mediante la curva CalPal2007-Hulu (Weninger y Jöris 2004) para precisar en la escala cronoestratigráfica global del Pleistoceno superior y el Holoceno sus episodios edafosedimentarios. Hemos comparado las curvas de probabilidad acumulada de las fechas calibradas con los eventos propuestos por el GIC005 (Lowe et al. 2008), con especial atención a la fase glacial o estadial GS 2 y la fase interestadial GI

\begin{tabular}{|c|c|c|c|c|c|c|}
\hline Yacimiento & Nivel & Episodio & Muestra & Laboratorio & Datación BP & CalBP p(95\%) \\
\hline Colls & IV & Colls D & Carbón & GifA 95571 & $12.490 \pm 120$ & $15350-14350$ \\
\hline Colls & IV & Colls D & Carbón & GifA 95544 & $12.150 \pm 120$ & $14790-13710$ \\
\hline H. Boquera & II & Boquera B & Carbón & OxA-13595 & $12.250 \pm 60$ & $14810-13890$ \\
\hline H. Boquera & II & Boquera B & Carbón & OxA-23646 & $11.850 \pm 45$ & $13850-13570$ \\
\hline H. Boquera & II & Boquera B & Carbón & OxA-23645 & $11.775 \pm 45$ & $13790-13550$ \\
\hline Filador & $8-9$ & & Carbón & OxA-8660 & $11.000 \pm 55$ & $13080-12720$ \\
\hline Filador & $8-9$ & & Carbón & OxA-8659 & $10.880 \pm 60$ & $12940-12700$ \\
\hline
\end{tabular}

Tab. 1. Relación de dataciones radiocarbónicas de los yacimientos Els Colls y L'Hort de la Boquera (Paleolítico Superior Final), y Filador (Epipaleolítico microlaminar), situados en el valle medio del río Montsant (Priorat, Tarragona).

Trab. prehist., 71 , N. ${ }^{\circ} 2$, julio-diciembre 2014, pp. 242-260, ISSN: 0082-5638

doi: $10.3989 /$ tp.2014.12133 
1. Además, para enmarcar dicha secuencia, hemos contrastado sus resultados con las dataciones del abrigo de Els Colls, adscritas al Paleolítico superior final, y con las correspondientes a los niveles del Epipaleolítico microlaminar del abrigo de El Filador (Tab. 1).

L'Hort de la Boquera, por su cronoestratigrafía, se situaría a finales del Pleistoceno superior final, es decir, en las postrimerías del MIS 2 (Fig. 6). La secuencia sedimentaria se inicia con el episodio Boquera D (nivel IV) de tipo fluvial, del que no contamos con evidencias arqueológicas. Tras un hiato, le sucede el episodio Boquera C (nivel III), también de génesis fluvial, pero con un régimen hídrico de menor intensidad. Por el momento, no podemos concretar su adscripción cronocultural. Tras otra interrupción, el registro continúa con el episodio Boquera B (nivel II). Tres dataciones sitúan parte de su sedimentación en la horquilla de 1080 años, entre 14670 y 13590 cal BP $(2 \sigma)$. Ello es un claro reflejo de una sedimentación lenta, propia de llanura de inundación. La formación de un horizonte A con un elevado contenido de materia orgánica procedente de vegetación de plantas superiores denota, ya de por sí, una estabilidad geomorfológica. Se le añade una importante actividad antrópica, documentada por varios episodios de combustión o muy posiblemente incendios. Cronoestratigráficamente, se iniciaría en la primera pulsación templada GI 1e o Bölling, y continuaría hasta el GI 1c, en el Alleröd inicial.

Una discontinuidad estratigráfica separa el nivel II del I (episodio A). Un contacto erosivo procedente de un aporte de ladera, quizás como resultado de la pulsación fría del GI $1 b$, marcaría el final de la secuencia. A partir de este episodio, el poblamiento del sector del valle medio del río Montsant se localiza en el abrigo del Filador, en los niveles 8-9, con industrias correspondientes al Epipaleolítico y enmarcadas en el GI-1a o Alleröd (Fullola et al. 2012).

\section{LAS EVIDENCIAS DE LA OCUPACIÓN HUMANA}

Como hemos indicado en la descripción estratigráfica, el nivel II es el único con material arqueológico y muy rico. La excavación en extensión de sus primeros $30 \mathrm{~cm}$ nos ha permitido identificar varios momentos de ocupación, con sus respectivas estructuras, y comenzar a estudiar la distribución espacial de los restos arqueológicos aparecidos.

Como es habitual en los yacimientos del área del Montsant, la industria lítica es la más característica y abundante de la ocupación. Los $20 \mathrm{~m}^{2}$ en curso de excavación han proporcionado 24.182 elementos de sílex, pizarra y calcárea. El sílex con pátina blanca es muy frecuente en la zona. Las alteraciones térmicas principales en las piezas $(6 \%)$ son las cúpulas.

Predominan las lascas $(42,3 \%)$, con talón liso en su mayoría, los fragmentos (elementos líticos informes) también tienen un porcentaje apreciable $(25,1 \%)$. Las lascas fragmentadas (lasca rota que conserva el talón) y los fragmentos de lasca (elemento con morfología de lasca, pero sin la parte proximal que contiene el talón) tienen porcentajes menores. Hay córtex, en general marginal en un $18,2 \%$ de los elementos líticos estudiados (Tab. 2).

\begin{tabular}{|l|r|c|}
\hline \multicolumn{1}{|c|}{ SOPORTE } & $\begin{array}{c}\text { N. }^{{ }^{\circ} \text { EFEC- }} \\
\text { TIVOS }\end{array}$ & $\begin{array}{c}\text { PORCEN- } \\
\text { TAJE }\end{array}$ \\
\hline LASCAS & 10.231 & $42,00 \%$ \\
\hline FRAGMENTOS & 6.078 & $25,13 \%$ \\
\hline FRAG. DE LASCA & 4.303 & $17,70 \%$ \\
\hline LASCAS FRAG. & 3.284 & $13,58 \%$ \\
\hline NÚCLEOS & 243 & $1,00 \%$ \\
\hline FRAG. NÚCLEO & 26 & $0,12 \%$ \\
\hline CANTOS & 17 & $0,07 \%$ \\
\hline TOTAL & $\mathbf{2 4 1 . 2 3 1}$ & \\
\hline
\end{tabular}

Tab. 2. Tipos de soportes de la industria de L'Hort de la Boquera (Priorat, Tarragona).

De estos 24.182 elementos líticos tallados 756 $(2,15 \%)$ son piezas retocadas. Comprenden 783 tipos primarios (752 monotipos, 14 piezas dobles y 1 pieza triple. Total 783$)$.

El retoque abrupto $(50,3 \%)$ supera algo al simple $(46 \%)$. Los buriles representan solo el $2,2 \%$ y el retoque sobreelevado el $1,6 \%$.

Dominan los raspadores $(29,9 \%)$ y elementos de dorso rebajado (40,3\%: $25,5 \%$ láminas y $14,4 \%$ puntas). Truncaduras (7\%) y denticulados $(8,8 \%)$ son significativos. Hay buriles sobre fractura, sobre retoque y diedros (Figs. 7 y 8 ). 


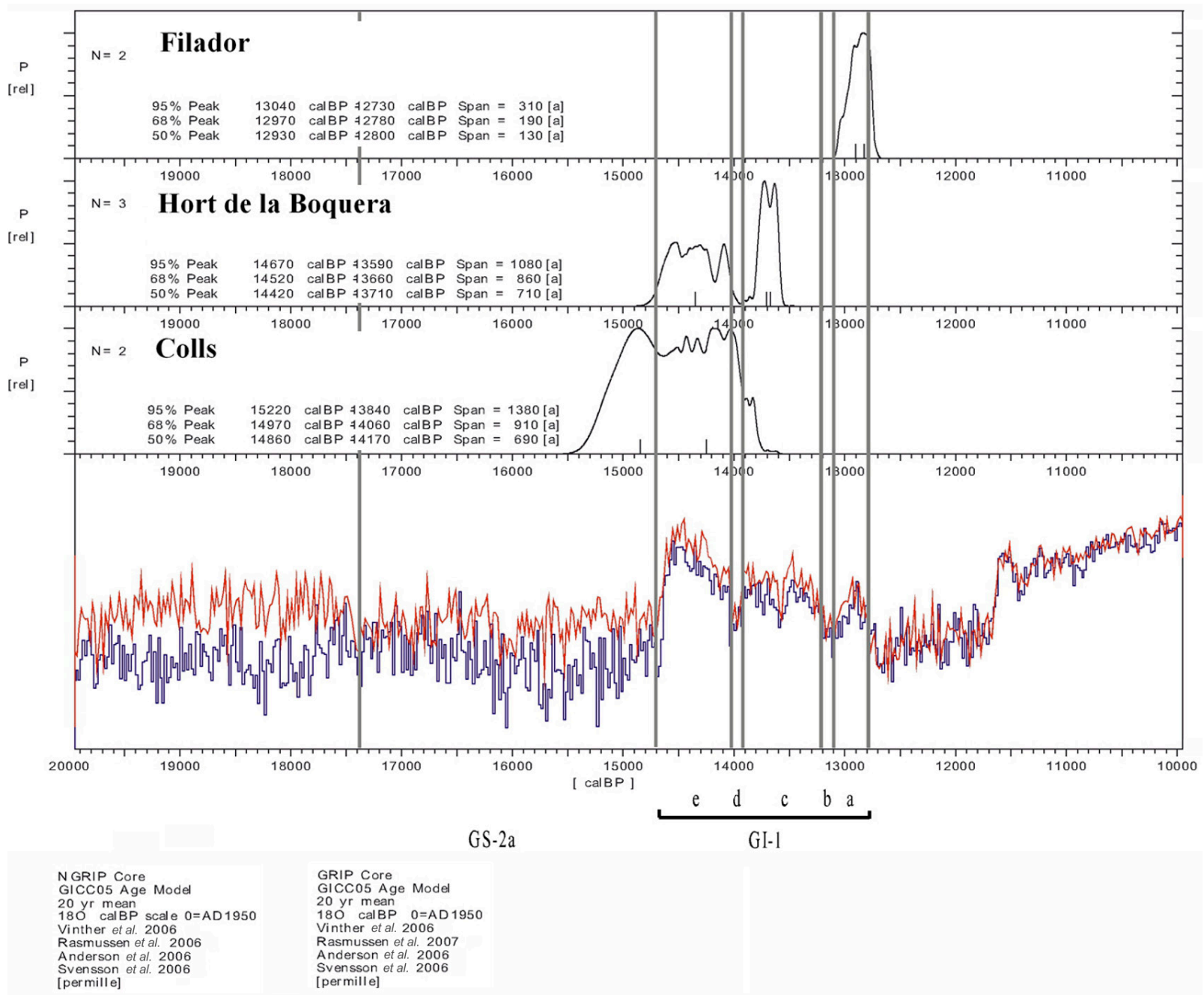

Fig. 6. Dataciones de Els Colls, L'Hort de la Boquera y Filador, y sus curvas de probabilidad obtenidas a partir de la calibración CalPal2007- Hulu y su comparación con las curvas de variación de $\delta^{18} \mathrm{O}$ de los sondeos de NGRIP y GRIP según GICC05 Age Model (Lowe et al. 2008).

Según M. Langlais (2010) las materias primas utilizadas proceden del entorno inmediato del asentamiento. Las minoritarias (esquisto, lidita, cuarzo, ...) se utilizan para el macroutillaje y el sílex para el resto de la industria, que se fabrica en el propio yacimiento.

Se buscaba obtener pequeñas láminas, estrechas y rectilíneas, de morfología triangular, sin excluir otros tipos de soporte como lascas laminares y láminas. Para las puntas de dorso se escogen láminas pequeñas, para los raspadores láminas retocadas y para las muescas alargadas.
Durante todo el proceso se utiliza el percutor duro, bien identificado en la excavación.

Este esquema de talla, algo alejado de la norma del Magdaleniense final al uso que le corresponde por las dataciones (véase más abajo), se ha constatado en otros yacimientos del Paleolítico superior de la zona como la cova de Els Colls (Fullola et al. 1993).

Destacamos el hallazgo de tres plaquetas de pizarra. Dos de forma redondeada con los bordes biselados y caras planas tienen toda una serie de trazos paralelos, perpendiculares, etc. Sus medi-

Trab. prehist., 71, N. ${ }^{\circ}$ 2, julio-diciembre 2014, pp. 242-260, ISSN: 0082-5638

doi: $10.3989 /$ tp.2014.12133 


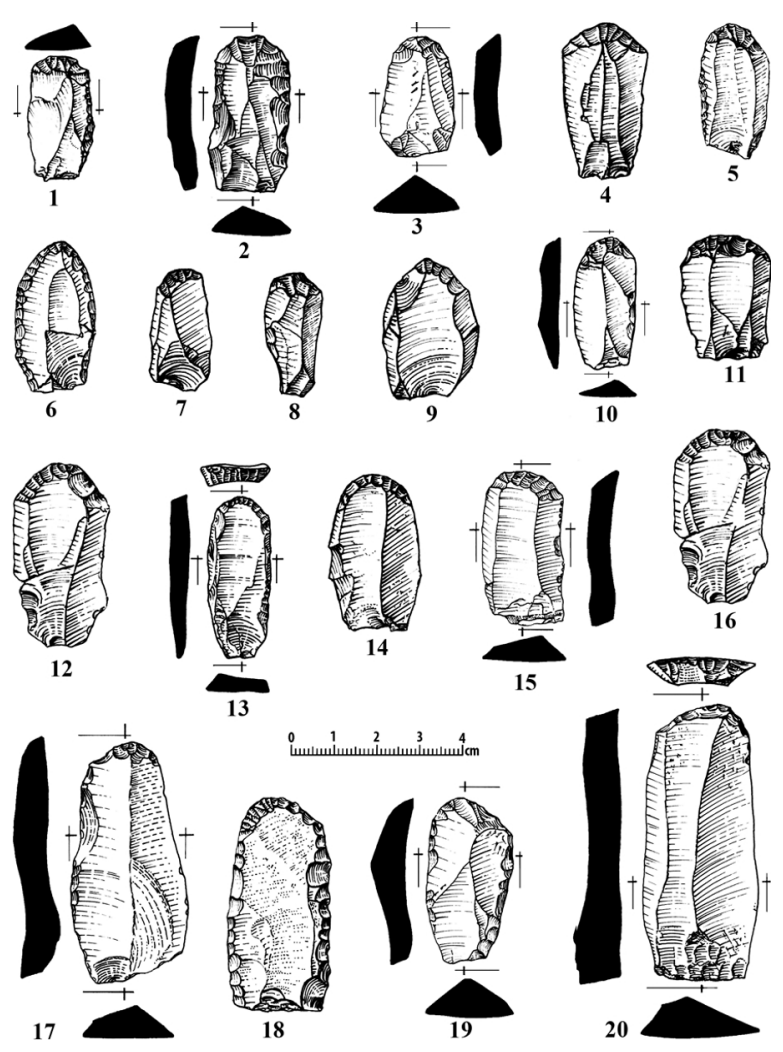

Fig. 7. Raspadores del nivel II del Abrigo de l'Hort de la Boquera (Priorat, Tarragona) (dibujos de R. Álvarez).

das son $72 \times 70 \times 10 \mathrm{~mm}$ y $66 \times 52 \times 11 \mathrm{~mm})$. La tercera de pequeñas dimensiones $(58 \times 42 \times 10 \mathrm{~mm})$ y con superficies de roce está alterada por el fuego. Al estar en estudio no podemos aportar más datos sobre su utilidad o significado.

Hay varias zonas de talla y, por el momento, dos estructuras de combustión. Son de forma irregular, casi ovalada, delimitada por estructuras de piedra. Tienen función culinaria.

Las dataciones radiocarbónicas, ya citadas en el epígrafe anterior, se realizaron en el Research Laboratory for Archaeology and History of Art de la Universidad de Oxford. Las tres fiables se hicieron sobre muestras de carbón: OxA-13595 (2004): $12250 \pm 60$ BP; OxA-23646 (2011): $11850 \pm 45$ BP y OxA-23645 (2011): $11775 \pm 45$ BP. Las fechas calibradas con una probabilidad del $68 \%$ son $14350 \pm 230$ cal BP, $13710 \pm 70 \mathrm{cal}$ $\mathrm{BP}$ y $13670 \pm 60$ cal BP respectivamente. Otra datación, realizada en 1992, a partir de restos de carbón obtenidos del muestreo sedimento-

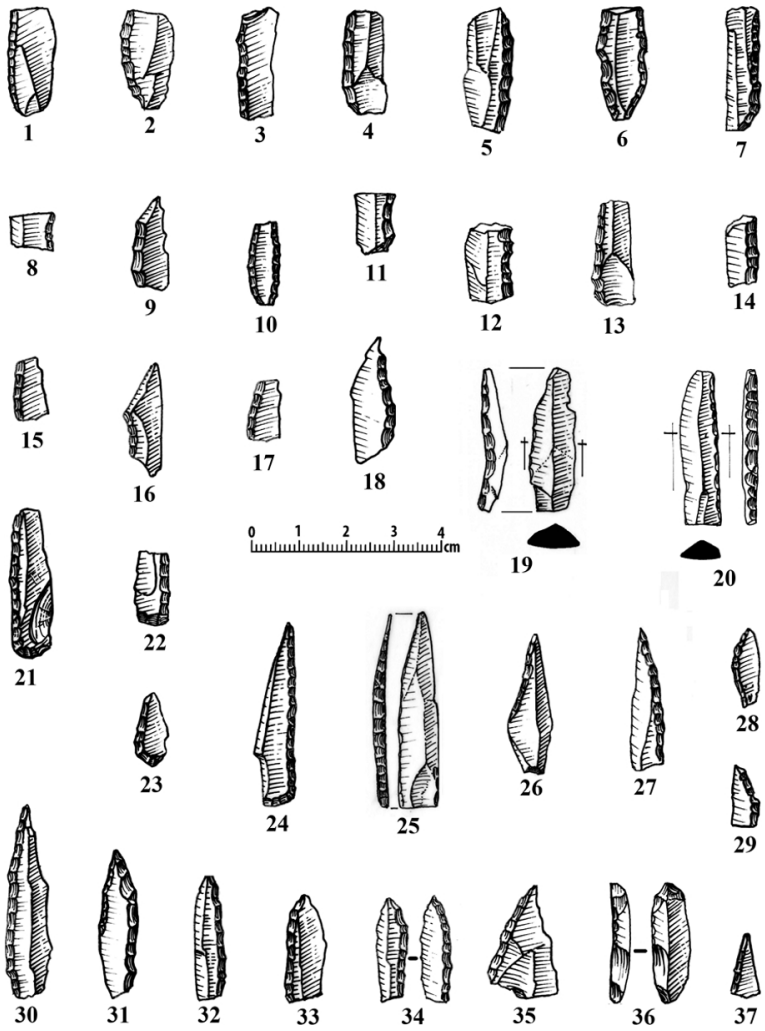

Fig. 8. Elementos de dorso del nivel II del Abrigo de l'Hort de la Boquera (Priorat, Tarragona) (dibujos de R. Álvarez).

lógico no se considera fiable por su procedencia: GIF10026: $9420 \pm 80$ BP.

\section{ESTUDIOS PALEOBIOLÓGICOS}

\subsection{Botánica}

La conservación de la materia orgánica es muy deficiente en todos los yacimientos de la zona del Montsant. Nuestros análisis arqueobotánicos (antracología, fitolitos) y faunísticos (mamíferos y moluscos terrestres y marinos) para conocer la evolución paleoecológica del yacimiento no dieron resultados definitivos.

Los estudios antracológicos se basan en los carbones identificados en las campañas de 1998, 2003 y 2008, por lo que consideramos los resultados como representativos del panorama paleovegetal de la zona. Los resultados muestran un conjunto homogéneo, con 13 fragmentos de $\mathrm{Pi}$ - 
nus tipo sylvestris, 1 de Juniperus y 2 indeterminables. El primero agrupa tres especies de montaña Pinus uncinata (pino negro), Pinus sylvestris (pino albar) y Pinus nigra (pino negral) distribuidos en la actualidad a diferentes altitudes (Blanco et al. 1998). Por la semejanza de sus características anatómicas utilizamos una única categoría para su identificación. Hoy en el Montsant encontramos Pinus nigra ssp. salzmanni y Pinus sylvestris. El género Juniperus también agrupa especies indistinguibles a partir de su estructura celular. En la zona encontramos Juniperus oxycedrus y Juniperus phoeniceae.

Pinus tipo sylvestris es el taxón más común y recurrente en las secuencias pleistocenas del noreste de la Península Ibérica (Allué 2009; Allué et al. 2012a). Las comunidades forestales de pino se extienden desde el litoral hasta el Pirineo durante algunas fases del Pleistoceno superior (Allué et al. 2012b; Daura et al. 2013). La mejora climática a partir del Tardiglaciar reduce la extensión de coníferas a favor de taxones mesotermófilos. Sus comunidades se caracterizan principalmente por la presencia de Prunus, Rhamnus cathartica/saxatilis y Acer. La xericidad en las zonas meridionales del noreste peninsular, situadas en el interior, parece mayor que en las septentrionales o litorales (Allué et al. 2007). Los datos antracológicos de secuencias próximas a L'Hort de la Boquera, como las de Els Colls, Molí del Salt, Font Voltada o Filador, muestran de forma más clara como las formaciones de Rosaceae y, principalmente, del género Prunus desplazan a las de Pinus t. sylvestris como taxones más significativos. Las prunoideas se presentan en formaciones arbóreo / arbustivas de carácter pre-forestal, cuya expansión tendrá lugar en la transición Pleistoceno-Holoceno, con un incremento notable a partir del Holoceno (Allué et al. 2012; Allué et al. 2012b; Henry et al. 2013). Los datos antracológicos obtenidos en Molí del Salt y Els Colls nos permiten sugerir que durante el Paleolítico superior de L'Hort de la Boquera las formaciones forestales de Pinus tipo sylvestris todavía son dominantes. Además otros datos paleoecológicos insinúan otras formaciones vegetales, como bosques de ribera o zonas abiertas ocupadas por herbáceas, reflejo de un paisaje en mosaico (Bergadà 1998; Burjachs 2009).

En este contexto ambiental, paleoecológico, los recursos forestales se explotaban según su abundancia y disponibilidad en el entorno inme- diato. La leña se recogía probablemente para un uso inmediato de carácter fungible. La selección del pino, un buen productor de biomasa muerta de fácil acceso, es recurrente durante buena parte del Pleistoceno. El incremento de taxones mesotermófilos, en buena medida productores de especies comestibles, modificará las estrategias de explotación del combustible. Esto se refleja de forma clara en el Mesolítico. En cambio, en fases anteriores los registros antracológicos son más homogéneos y con escasa variabilidad taxonómica.

La presencia de fitolitos se probó en una muestra cercana a $1 \mathrm{gr}$, recogida en la parte superior del nivel arqueológico de la zona más externa del yacimiento. Pero el número de fitolitos por gramo de AIF (fracción no soluble al ácido), unos 16.000, era excesivamente bajo. Tampoco se ha identificado su morfología en una cantidad suficiente para interpretar de modo fiable los restos vegetales (Albert, R. M. y Weiner, S. 2001). Se concluyó que la ausencia de fitolitos no se debía a su disolución durante el tratamiento del sedimento, sino a la ausencia de vegetales en la muestra.

\subsection{Fauna}

Solo presentamos la relación de algunas especies aparecidas (mamíferos y malacofauna continental y marina), y su contextualización respecto a las identificadas en yacimientos próximos y de cronología similar, dado el reducido número de elementos faunísticos recuperados.

Durante estos años se han recuperado un total de 99 elementos en el yacimiento: $23(23,23 \%)$ son determinables desde el punto de vista tafonómico y $76(76,76 \%)$ no. El estado de conservación es muy precario y las alteraciones diagenéticas importantes. Las medidas de los restos no determinables nos han aproximado a su identificación. Hay 2 de herbívoros (dentición), 27 de macrofauna de tamaño medio, 41 de macrofauna sin más precisión, 2 de mesofauna y 4 restos que no se pueden identificar en absoluto.

Esta distribución y su comparación con los restos determinables sugieren que los herbívoros y los restos de macrofauna de tamaño medio podrían pertenecer a pequeños bóvidos. Ningún resto de macrofauna se puede atribuir, con seguridad, a équidos, grandes bóvidos o grandes cér- 
vidos. También destaca la irrelevancia de la mesofauna, es decir, de animales con tamaño similar al de los lepóridos.

El número de especímenes identificados (NISP) es 6 Capra pyrenaica, 13 pequeños bóvidos y 4 Oryctolagus cuniculus con un solo individuo por taxón.

El material aparece totalmente fragmentado, salvo un astrágalo de cabra montés. Las astillas recuperadas tienen de promedio $2 \mathrm{~cm}$ de longitud máxima. La primera causa de la fragmentación es la intervención antrópica. El máximo aprovechamiento de los recursos alimentarios supone la destrucción de los huesos para la extracción del tuétano y para la obtención de grasas y colágeno, actividades muy corrientes en los yacimientos de cazadores-recolectores (Binford 1978). La segunda son los fenómenos fosildiagenéticos, como una fuerte deshidratación y carbonatación del material. A ambas se añade el alto grado de alteración térmica del conjunto faunístico: la coloración de numerosos restos calcinados supone temperaturas superiores a los $600{ }^{\circ} \mathrm{C}$ (Stiner et al. 1995). Es casi imposible identificar las partes anatómicas. La mayoría del conjunto son piezas dentarias. El esqueleto postcraneal está representando solo por un fragmento de radio y un astrágalo. De todas maneras nos parece que las carcasas pudieron llegar completas al yacimiento.

La malacofauna continental cuenta con 486 elementos: 87 están enteros y 328 son fragmentos que, en 71 casos corresponden a individuos irrepetibles. Por este motivo, el NMI se fija en 158 elementos. Este recuento debe estar afectado por el proceso sedimentario fluvial, que transporta con gran facilidad las conchas, muy ligeras y con una cámara de aire interior que aumenta su flotabilidad, así como por los procesos diagenéticos y de recuperación durante la excavación. Todo ello complica establecer la importancia de la malacología continental en la dieta de las comunidades prehistóricas ocupantes de L'Hort de la Boquera. Además no todas las especies identificadas tienen valor culinario: pueden descartarse los taxones que no corresponden al grupo de los grandes helícidos. La distribución taxonómica de los restos es la siguiente Cepaea nemoralis 464, Pomatias elegans 1, Rumina decollata 12, Xeroplexa sp 7 y Chondrinae 1. Rumina decollata o Pomatias elegans son especies con comportamientos excavadores y, en nuestro caso, no tenemos la certeza de su sincronía con la formación del nivel geológico.

Centramos nuestro estudio en Cepaea nemoralis. El elevado grado de fragmentación podría hacernos sospechar un origen no antrópico, pero el número de ejemplares enteros es significativo. La población es polimorfa y de medidas muy homogéneas (25-27 $\mathrm{mm}$ de diámetro máximo de la concha y 16-19 mm de altura). Todos los elementos analizados tienen un diseño de 5 bandas (12345) y, en algunos, la segunda y tercera están fundidas (1(23)45). Algunos biólogos interpretan este modelo, que tiende a oscurecer la superficie de la concha, como una adaptación a ambientes más forestales. No es una conclusión muy clara (Jones et al. 1977). De hecho, no coincide mucho con los datos paleobotánicos antes mencionados. Sí parece observarse un cierto gradiente latitudinal en los conjuntos de Cepaea nemoralis del Pleistoceno final-Holoceno inicial: mientras en los yacimientos septentrionales (sur de Francia o los Pirineos) las conchas de dichos caracoles tienden a carecer de bandas (Dourgne, Arques, Balma de la Margineda) en las latitudes medias hay un cierto equilibrio entre las que las presentan y las que no (Balma del Gai) (Lloveras et al. 2011). En L'Hort de la Boquera, como se ha mencionado, todas las tienen. Esta homogeneidad nos hace pensar en áreas de captación muy concretas. Actualmente Cepaea nemoralis no abunda mucho en la solana donde se sitúa L'Hort de la Boquera, siendo habitual en los valles menos soleados de la sierra del Montsant. En cambio en la zona del yacimiento predomina hoy en día Sphinterochila candidissima, especie mucho más termófila.

De momento solo tenemos un ejemplar de malacofauna marina: un fragmento de valva del género Glycymeris, indicador de algún tipo de conexión con la costa. Este género aparece en yacimientos cercanos de cronología similar (Molí del Salt). Consideramos interesante plantearse el significado simbólico y lingüístico de Glycymeris para las comunidades prehistóricas de finales del Pleistoceno en la zona interior de Tarragona.

\subsection{Arte mueble}

Uno de los hallazgos más significativos de la campaña de excavaciones del 2011 fue un riñón calizo con motivos grabados de tipo figurativo, que enriquece el exiguo registro de arte mobiliar 
del final del ciclo paleolítico, conocido hasta la fecha en el noreste de la Península Ibérica. El riñón es de morfología irregular y bordes redondeados. Mide unos 30,9 × 20,7 × $17 \mathrm{~cm}$ de espesor. Los 5 motivos identificados se concentran en la cara de superficie más regular. La técnica es el grabado simple de tipo modelante. Destaca la representación naturalista y completa de un ave orientada hacia la derecha, que ocupa el centro del dispositivo gráfico. Mide 15,3 cm de longitud máxima del extremo del pico al de una de sus patas.

El modelado de la figura central recoge los detalles anatómicos más característicos de la silueta de un ave. La cabeza es pequeña, definida con trazos redondeados, detallando el pico y la línea de mandíbula. El cuello es alargado y sinuoso y el cuerpo macizo y redondeado. Se presta especial atención al plumaje de la cola, corta. Las patas largas, en disposición paralela, rematan en dedos poco naturalistas. El único detalle anatómico interno es el plumaje de las alas (Fig. 9).
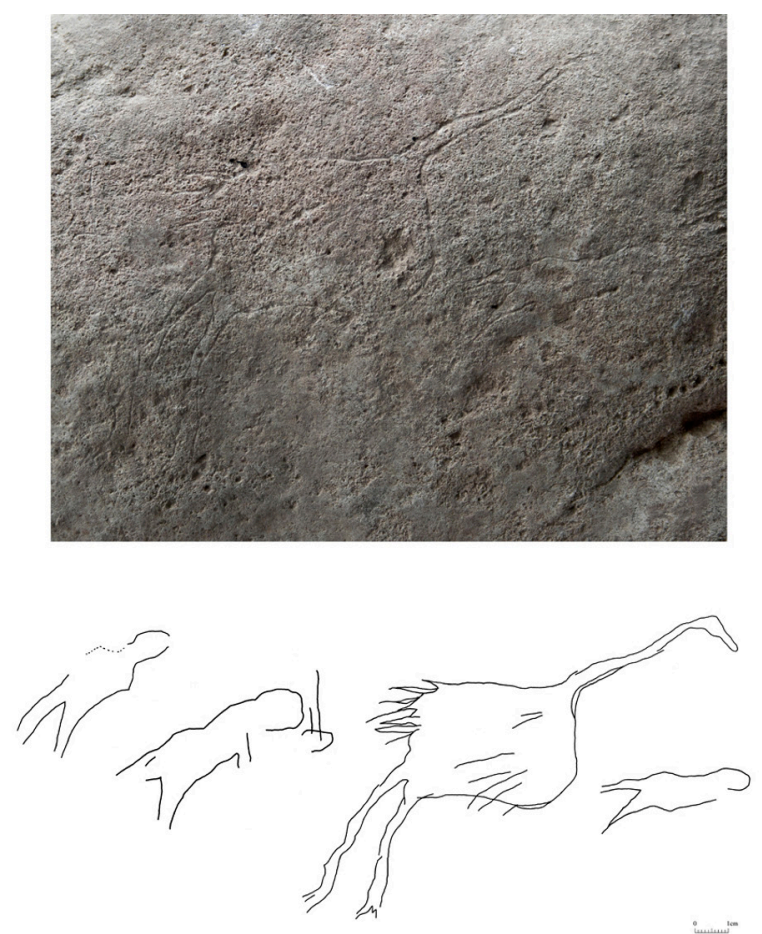

Fig. 9. Fotografía y calco de los grabados centrales de l'Hort de la Boquera (Priorat, Tarragona). Destaca un ave modelada con el estilo del final del ciclo artístico paleolítico. Mide 15,3 cm de longitud máxima del extremo del pico al de una de sus patas.
Está en curso un estudio amplio de la pieza, incluyendo la descripción de la serie de motivos grabados, de menor tamaño y naturalismo, que rodean el ave, así como su posible interpretación y valoración en el contexto regional y global. Avanzamos algunos resultados respecto a su identificación taxonómica.

Las representaciones de aves en el arte paleolítico son pocas: no superan el centenar. Abundan más en el arte mueble que en el parietal (Crémades et al. 1997). Según Nicolau-Guillaumet (2008), un 35\% corresponde a aves acuáticas, incluyendo anátidas y zancudas, un $9,5 \%$ a las rapaces, un $6 \%$ a los paseriformes, principalmente córvidos, y poco más de un $1 \%$ a las galliformes. La taxonomía de un $48 \%$ de las representaciones sería inidentificable. Seguramente entre las "zancudas" el autor incluye aves de comportamiento no estrictamente acuático, o incluso especialmente terrestre, como muchas especies del orden de las gruiformes, al que ciertamente corresponde el grabado de L'Hort de la Boquera. Las representaciones paleolíticas asignadas a este orden suelen clasificarse como avutardas (familia Otididae) o grullas (familia Gruidae). Serían avutardas las representaciones de Gourdan, La Madeleine, Puy de Lacam, un ave de Laugerie-Basse y Lortet y, en cambio, grullas las de Arancou, la Vache, un ave distinta a la ya citada en Laugerie-Basse, Gargas y Belvis (Crémades et al. 1997). Las avutardas tendrían cabezas más grandes, picos más puntiagudos, cuellos más cortos y gruesos y patas también algo más cortas y gruesas que las grullas. Por su parte las cabezas de las grullas serían más pequeñas con picos algo más alargados y cuellos y patas más estrechos y largos. Los cuellos largos, estrechos y serpentiformes también caracterizan una representación de anátidas de Gourdan y otra de Teyjat, clasificadas como cisnes.

Estos parámetros restringirían la taxonomía del ave de L'Hort de la Boquera a dos familias: Otididae y Gruidae. El pico de las otídidas, en especial de las avutardas, es relativamente más corto que el resto de la cabeza. El cuello, aunque largo, es substancialmente más corto que el cuerpo y se engrosa sobre todo en la base, por la llamada gola. Las patas son largas pero de relativa robustez al ser animales de comportamiento muy terrestre. Los pies acaban en tres dedos. Los machos, barbados, extienden el plumaje pectoral y de la cola en la fase de exhibición (Alonso y 
Palacín 2009). Las grullas son de complexión más grácil. Las proporciones de cabeza y pico son más equilibradas. Difieren de las otítidas en que el cuello y las patas son más largos que el cuerpo. El cuello puede adoptar una sinuosidad serpentiforme.

Hoy en día, en Europa, las Otididae son la avutarda (Otis tarda), el sisón (Tetrax tetrax) y la hubara (Chamydotis undulata). Las Gruidae incluyen la grulla común (Grus grus) y la grulla damisela (Anthropoides virgo) (Peterson et al. 1967) y, como especies fósiles pleistocenas, Grus primigenia, Grus bohatshevi y Grus melitensis (Arribas 2004).

Sobre la base de la comparación de los criterios biológicos y de la tradición clasificatoria del arte paleolítico creemos que el grabado central del bloque de L'Hort de la Boquera representa un espécimen de la familia de las grullas.

\section{CONSIDERACIONES FINALES}

Queda mucho trabajo por hacer, y más campañas de excavaciones, en el asentamiento de L'Hort de la Boquera, pero podemos ofrecer una serie de conclusiones. El valle medio del río Montsant adquiere un especial interés arqueológico al ubicarse en ese espacio ese asentamiento y otros ya conocidos y publicados, total o parcialmente, como Els Colls, El Filador, El Planot, Cova del Boix, Bauma de l'Auferí o Cova de la Taverna (Fullola 1990; Adserias et al. 1996), que documentan un poblamiento que va desde el $\mathrm{Pa}$ leolítico Medio hasta el Neolítico.

En L'Hort de la Boquera, según los resultados actuales, solo hay un estrato arqueológico, aunque en las proyecciones se pueden apreciar dos niveles de ocupación, separados por un pequeño hiatus a los $60 \mathrm{~cm}$ de profundidad, respecto a nuestro nivel 0 . Estos niveles de ocupación son muy ricos en material arqueológico. La industria lítica muestra un claro binomio raspador-elementos de dorso (aquí incluimos láminas, puntas y elementos de dorso truncados). Encontramos elementos típicos del Paleolítico superior final, como las laminitas de dorso rebajado rectangulares, un porcentaje no despreciable de buriles, entre los que encontramos buriles diedros, y también numerosas truncaduras. La contraposición entre estas características industriales y el gran tamaño de las piezas se explica por la cercanía a las fuentes de materia prima, situadas en el término de Ulldemolins, a poco más de $6 \mathrm{~km}$ de distancia. A su vez, la tecnología utilizada para la fabricación de las piezas no sigue las pautas que se observan para el Magdaleniense final clásico.

La ausencia de industria ósea, por el momento, se compensa por la presencia de arte mueble sobre soporte lítico. Es un hallazgo excepcional en el Paleolítico superior catalán, tanto por su temática, la representación de un ave, como por la escasez de ejemplares, limitados a las placas grabadas del yacimiento del Molí del Salt. El estilo del grabado de L'Hort de la Boquera se corresponde con el estilo del final del ciclo artístico paleolítico, que dará paso a la fase no figurativa del Epipaleolítico / Mesolítico con ejemplos tan claros como la serie de La Cocina o el más cercano guijarro con seis líneas pintadas del abrigo de El Filador (Fullola y Couraud 1984).

Los estudios paleovegetales efectuados muestran que, en toda esta zona de la Cataluña meridional, las formaciones de Pynus silvestris siguen siendo la vegetación dominante junto con bosques de ribera y zonas abiertas de herbáceas. El estudio arqueofaunístico proporciona otros resultados interesantes aún escaseando los restos. Entre los vertebrados el principal recurso cinegético es la cabra montés siguiendo una tendencia ya evidenciada en los yacimientos de cazadores-recolectores del Paleolítico superior final y del Epipaleolítico del valle del Monsant. Seguramente la explotación serían estacional, muy probablemente aprovechando el movimiento de las manadas entre el valle y los puntos culminantes de las sierras circundantes. Ello explicaría también la concentración, parece que estratégica, de los yacimientos en las convergencias de los barrancos laterales con el río Montsant (Garcia-Argüelles et al. 2005). L'Hort de la Boquera es uno de los yacimientos del Paleolítico superior final, asociados a una orografía abrupta, donde la preferencia por cazar la cabra montés se contrapone a la opción por el ciervo propia de los situados en la montaña baja (Fullola et al. 2012).

La presencia de gasterópodos terrestres, en concreto de la especie Cepaea nemoralis, generalizada como recurso alimentario en yacimientos de cronología posterior, da al yacimiento un toque de modernidad respecto a otros del Paleolítico superior final en Cataluña, canónicamente 
magdalenienses según sus industrias. Este tipo de yacimientos, que comprende L'Hort de la Boquera, Els Colls (Fullola et al. 1993) y el Molí del Salt (Vaquero 2004), evidencia la diversificación de los recursos alimentarios que caracterizará el Epipaleolítico cuando aumentan de modo progresivo los gasterópodos terrestres y las presas pequeñas como los lepóridos y inician su presencia los restos carbonizados de frutos silvestres (Allué et al. 2010).

Las dataciones de yacimientos típicamente magdalenienses como Parco y Montlleó se concentran en el GS 2a i GS2b, mientras que las de L'Hort de la Boquera, Els Colls y Molí del Salt se agrupan en torno a GI-1 (Fullola et al. 2012), como ya se ha comentado. En conclusión, L'Hort de la Boquera es un asentamiento del Paleolítico superior final con unas características propias de la zona meridional catalana, en concreto de las comarcas centrales de Tarragona.

\section{AGRADECIMIENTOS}

Este trabajo se enmarca en el proyecto HAR2011-26193 del Ministerio de Educación y Ciencia (MEC) y en el Grup de Recerca de Qualitat SGR2009-01145 de la Generalitat de Catalunya. Otras fuentes de financiación proceden del Servei d'Arqueologia i Paleontologia de la misma Generalitat de Catalunya que las ha venido asignando, sin interrupción desde 1998, dentro de las programaciones plurianuales de excavaciones presentadas por el Seminari d'Estudis i Recerques Prehistòriques (SERP) de la Universitat de Barcelona (UB) y aprobadas por dicho organismo. El sr. Ramón Álvarez, dibujante del Departamento de Prehistoria, Historia Antigua y Arqueología de la UB ha reproducido la industria lítica. También expresamos nuestro agradecimiento a l'Institució Catalana de Recerca i Estudis Avançats (ICREA) de la Generalitat de Catalunya y a los Centros Científicos y Tecnológicos de la Universidad de Barcelona (CCiT-UB) por la utilización del Servicio de Microscopía electrónica (ESEM-EDAX) y a la dra. Rosa M. Poch del Departamento de Medio Ambiente y Ciencias del Suelo de la Universidad de Lleida por sus comentarios y sugerencias sobre las biomineralizaciones de fibrasagujas de calcita.

\section{BIBLIOGRAFÍA}

Adserias, M.; Bartrolí, R,; Cebrià, A.; Farell, D.; Gamarra, A. y Miró, J. M. 1996: "La Balma de l'Auferí (Margalef de Montsant, Priorat): un nou assentament prehistòric a la Vall del Montsant", Tribuna d'Arqueologia 1994-95: 40-50.

Albert, R. M. y Weiner, S. 2001: "Study of phytoliths in prehistoric ash layers using a quantitative approach". En J. D. Meunier y F. Colin (eds): Phytolith: applications in Earth Sciences and human History: 251-266. Amsterdam.

Allué, E. 2009: "Estudios antracológicos en la vertiente sur del Pirineo y áreas circundantes durante el Tardiglaciar. Una aproximación de la arqueobotánica al conocimiento del medio vegetal y su aprovechamiento". En J. M. Fullola Pericot, N. Valdeyron y M. Langlais (eds.): Els Pirineus i les àrees circumdants durant el Tardiglaciar. Mutacions i filiacions tecnoculturals, evolució paleoambiental (16000-10000 BP). XIV Col-loqui internacional d'Arqueologia de Puigcerdà (Puigcerdà 2006): 163-181. Puigcerdà.

Allué, E.; Euba, I. y Rodriguez, A. 2012: “Cambios de paisaje y aprovechamiento de los recursos vegetales durante la transición Pleistoceno-Holoceno en el nordeste de la Península Ibérica". Cuaternario y Geomorfología 26 (3-4): 47-60.

Allué, E.; Ibáñez, N.; Saladié, P. y Vaquero, M. 2010: "Small prey and plant Explotation by late Pleistocene hunter-gatherers. A case study from northeast of the Iberian Peninsula". Archaeological and Anthropological Sciences 2 (1): 11-24.

Allué E.; Nadal J.; Estrada A. y García-Argüelles, P. 2007: "Los datos antracológicos de la Balma del Gai (Bages, Barcelona): una aportación al conocimiento de la vegetación y la explotación de los recursos forestales durante el Tardiglaciar en el NE peninsular". Trabajos de Prehistoria 64 (1): 87-97.

Allué, E.; Martínez-Moreno, J.; Alonso, N. y Mora. R. 2012: "Changes in the vegetation and human management of forest resources in mountain ecosystems at the beginning of MIS 1 (14,7-8 ka cal BP) in Balma Guilanyà (South-Eastern Pyrenees, Spain)". Comptes Rendus Palevol 11: 507-518.

Alonso, J. C. y Palacín, C. 2009: “Avutarda - Otis tarda". En A. Salvador (ed.): Enciclopedia Virtual de los Vertebrados Españoles. Sociedad de Amigos del MNCN, Museo Nacional de Ciencias Naturales, CSIC. Madrid http://www.vertebradosibericos.org/ aves.html (acceso 11-VI-2014).

Arribas, O. 2004: Fauna y paisaje de los Pirineos en la era glaciar. Lynx edicions. Barcelona.

Bajnóczi, B. y Kovács-Kis, V. 2006: "Origin of pedogenic needle-fiber calcite revealed by micromorphology and stable isotope composition -a case

Trab. prehist., 71, N. ${ }^{\circ}$ 2, julio-diciembre 2014, pp. 242-260, ISSN: 0082-5638

doi: $10.3989 /$ tp.2014.12133 
study of a Quaternary paleosol from Hungary". Chemie der Erde 66: 203-212.

Bech, J.; Bartrolí, R.; Bergadà, M. M. y Garrigó, J. 1990: Sols d'ahir i d'avui. ed. Comissió Interdepartamental de Recerca i Innovació Tecnològica, Generalitat de Catalunya. Barcelona.

Bergadà, M. M. 1993: “Aproximación experimental a la actividad postdeposicional de los lumbrícidos sobre los niveles arqueológicos". IV Coloquio de Arqueología Espacial Procesos Postdeposicionales (Teruel. 1993): 363-369. Teruel.

Bergadà, M. M. 1998: Estudio geoarqueológico de los asentamientos prehistóricos del Pleistoceno Superior y el Holoceno inicial en Catalunya. British Archaeological Reports, International Series 742, Archeopress. Oxford.

Bergadà, M. M.; Cervelló, J. M. y Serrat, D. 1997: "Karst in conglomerates in Catalonia (Spain): morphological forms and sedimentary sequence types recorded on archaeological sites". Quaternaire 8 (2-3): 267-277.

Binford, L. R. 1978: Nunamiut Ethnoarchaeology. Academic Press. New York.

Blanco, E.; Casado, M. A.; Costa, M.; Escribano, R.; García, M.; Génova, M.;Gómez, A.; Gómez, F.; Moreno, J. C.; Morla, C.; Regato, P. y Sainz, H. 1998: Los bosques ibéricos. Una interpretación geobotánica. Planeta. Madrid.

Bullock, P.; Fedoroff, N.; Jongerius, A.; Stoops, G. y Tursina, T. 1985: Handbook for soil thin section description. Waine research publ. Wolverhampton.

Burjachs, F. 2009: "Paleoambient del Tardiglacial al sud dels Pirineus vist a través de la Palinologia". En J. M. Fullola-Pericot, N. Valdeyron y M. Langlais (eds.): Els Pirineus i les àrees circumdants durant el Tardiglaciar. Mutacions i filiacions tecnoculturals, evolució paleoambiental (16000-10000 BP). XIV Col-loqui internacional d'Arqueologia de Puigcerdà (Puigcerdà 2006): 151-162. Puigcerdà.

Courty, M. A.; Goldberg, P. y Macphail, R. I. 1989: Soils and micromorphology in archaeology. Cambridge University Press. Cambridge.

Crémades, M.; Pellicer, M. y Sanchidrián, J. L. 1997: "Nouvelles figurations d'oiseaux de l'art mobilier paléolithique franco-espagnol”. Paléo 9: 371-387.

Durand, N.; Curtis, H. y Canti, M. G. 2010: "Calcium carbonate features". En G. Stoops, V. Marcelino y F. Mees: Interpretation of micromorphological features of soils and regoliths. Elsevier. Amsterdam: 149-194.

Fullola, J. M. 1978: "L'Hort de la Boquera. Un nou jaciment a la Vall del Montsant". Boletín de la Real Sociedad Arqueológica Tarraconense ép. IV, fasc. 141-144: 3-14.

Fullola, J. M. 1990: "Abric dels Colls, Margalef de Montsant (Priorat)". Boletín de la Real Sociedad Arqueológica Tarraconense 12, ép.V: 140-142.
Fullola, J. M.; Bartrolí, R.; Bergadà, M. M.; Doce, R.; Garcia-Argüelles, P.; Nadal, J.; Rodón, T.; Adserias, M. y Cebrià, A. 1993: "Nuevas aportaciones al conocimiento del Paleolítico Superior en las comarcas meridionales y occidentales de Cataluña". En M. P. Fumanal y J. Bernabeu (eds.): Estudios sobre Cuaternario: medios sedimentarios, cambios ambientales, hábitat humano. Universidad de Valencia. Valencia: 239-247.

Fullola, J. M. y Couraud, C. 1984: "Le galet peint de l'abri du Filador (Catalogne, Espagne)". L'Anthropologie 88, 1: 119-123.

Fullola, J. M.; Mangado, X.; Tejero, J. M.; Petit, M. A.; Bergadà, M. M.; Nadal, J.; García-Argüelles, P.; Bartrolí, R. y Mercadal, O. 2012: "The Magdalenian in Catalonia (northeast Iberia)". Quaternary International 272-273: 55-77.

Garcia-Argüelles, P.; Nadal, J. y Fullola, J. M. 2005: "El Filador (Margalef de Montsant, Tarragona) y su contextualización cultural y cronológica en el nordeste peninsular". Trabajos de Prehistoria 62 (1): 65-83.

Garcia-Argüelles, P.; Serrat, D. y Bergadà, M. M. 1993: "Las terrazas fluviales del curso medio del río Montsant (Tarragona) y su relación con los asentamientos prehistóricos". El Cuaternario en España y Portugal. Actas de la 2. ${ }^{a}$ Reunión del Cuaternario Ibérico 1 (Madrid 1989): 493-499. Madrid.

Henry, A.; Valdeyron, N.; Bouby, L. y Théry-Parisot, I. 2013: "History and evolution of Mesolithic landscapes in the Haut-Quercy (Lot, France): New charcoal data from archaeological contexts". The Holocene 23, 1: 127-136.

Jones, J. S.; Leith, B. H.; Rawlings, P. 1977: "Polimosfhism in Cepaea: a problem with too many solutions?". Annual Review of Ecology and Systematics 8: 109-143.

Langlais, M. 2010: Les sociétés magdaléniennes de l'Isthme pyrénéen. Comité des Travaux Historiques et Scientifiques, collection Documents Préhistoriques 26. Paris.

Lloveras, L.; Nadal, J.; Garcia-Argüelles, P.; Fullola, J. M. y Estrada, A. 2011:"The land snail midden from Balma del Gai (Barcelona, Spain) and the evolution of terrestrial grastropod consumption during the late Palaeolithic and Mesolithic in Eastern Iberia". Quaternary International 244: 37-44.

Lowe, J. J.; Rasmussen, S. O.; Björck, S.; Hoek, W. Z.; Steffensen, J. P.; Walker, M. J. C. y Yu, Z. C. 2008: "Synchronisation of palaeoenvironmental events in the North Atlantic region during the Last Termination: a revised protocol recommended by the INTIMATE group". Quaternary Science Reviews 27: 6-17. 
Nicolau-Guillaumet, P. 2008: "Avifaune et art paléolithiques. Essai pour une bibliographie exhaustive". Alauda 76 (4): 287-298.

Peterson, R.; Mountfort, G. y Hollom, P. A. D. 1967: Guía de Campo de las aves de España y demás países de Europa. Omega. Barcelona.

Stoops, G. 2003: Guidelines for analysis and description of soil and regolith thin section. Soil Science Society of America, Inc Wisconsin. Madison.

Stoops, G.; Marcelino, V. y Mees, F. 2010: Interpretation of micromorphological features of soils and regoliths. Elsevier. Amsterdam.

Stiner, M. C.; Kuhn, S. L.; Weiner, S. y Bar-Yosef, O. 1995: "Differential burning, recrystallization and fragmentation of archaeological bone". Journal of Archaeological Science 22: 223-237.
Vaquero, M. 2004: Els darrers caçadors-recol-lectors de la Conca de Barberà: el jaciment del Molí del Salt (Vimbodi). Excavacions 1999-2003. MuseuArxiu de Montblanc i comarca. Montblanc.

Verrecchia, E. P. y Verrecchia, K. E. 1994: "Needlefiber calcite: a critical review and a proposed classification". Journal of Sedimentary Research A.64 (3): 650-664.

Weninger, B. y Jöris, O. 2004: “Glacial Radiocarbon Calibration. The CalPal Program”. En Th. Higham, Chr. Bronk Ramsey y Cl. Owen (eds.): Radiocarbon and Archaeology. Proceedings of the 4th Symposium Oxford 2002). Oxford University School of Archaeology Monograph 62. Oxford: 9-15.

Wright, V. P. 1986: "The role of fungal biomineralization in the formation of Early Carboniferous soil fabrics". Sedimentology 33 (6): 831-838. 